\title{
ВЛИЯНИЕ ТЕКСТУРИРОВАННЫХ ПРОДУКТОВ ИЗ ЗЕРНОВОГО СЫРЬЯ НА СОСТОЯНИЕ УГЛЕВОДНО-АМИЛАЗНОГО КОМПЛЕКСА В МУЧНЫХ СМЕСЯХ ДЛЯ ХЛЕБОБУЛОЧНЫХ ИЗДЕЛИЙ
}

\section{M.A. Yanova, N.V. Prisukhina, T.A. Gorbunova \\ THE INFLUENCE OF TEXTURED PRODUCTS FROM GRAIN RAW MATERIALS ON THE STATE OF CARBOHYDRATE-AMYLASE COMPLEX IN FLOUR MIXTURES FOR BAKERY PRODUCTS}

Янова М.А. - канд. с.-х. наук, доц. каф. товароведения и управления качеством продукции АПК Красноярского государственного аграрного университета, г. Красноярск.

E-mail: yanova.m@mail.ru

Присухина Н.В. - канд. техн. наук, доц. каф. технологий хлебопекарного, кондитерского и макаронного производств Красноярского государственного аграрного университета, г. Красноярск.

E-mail: nat3701@mail.ru

Горбунова T.A. - магистрант каф. технологий хлебопекарного, кондитерского и макаронного производств Красноярского государственного аграрного университета, г. Красноярск.

E-mail: tatyana.gorbunova20@mail.ru

Цель исследования - изучение влияния текстурированной муки на состояние уәлеводноамилазного комплекса в мучных смесях для производства хлеба. Задачи исследования: определить экспериментальньм путем число падений (ЧП) зерновых текстуратов; составить смеси с частичной заменой муки пшеничной на текстурированные продукты; изучить ЧП полученных смесей; провести экспериментальные исследования смесей при производстве хлеба. Число падения определяли согласно ГОСТ 27676 на приборе ПЧП-З. По показателю числа падения судили о состоянии углеводно-амилазного комплекса смеси. Смеси составлены из мелкой, средней и крупной фрракций муки. В пшеничную муку вносили следующие текстурать: ячменный, овсяный и пшеничный. Замену пшеничной муки на текстурат проводили в количестве от 5 до $25 \%$. ЧП мучных смесей в среднем уменьшилось на $8 \%$ в зависимости от крупности помола и вида вводимого текстурированного продукта, но все показатели остались в пределах требования
Yanova M.A. - Cand. Agr. Sci., Assoc. Prof., Chair of Merchandizing and Product Quality Control of AIC, Krasnoyarsk State Agrarian University, Krasnoyarsk.

E-mail: yanova.m@mail.ru

Prisukhina N.V. - Cand. Techn. Sci., Assoc. Prof., Chair of Technology of Baking, Confectionery and Macaroni Productions, Krasnoyarsk State Agrarian University, Krasnoyarsk.

E-mail: nat3701@mail.ru

Gorbunova T.A. - Magistrate Student, Chair of Technology of Baking, Confectionery and Macaroni Productions, Krasnoyarsk State Agrarian University, Krasnoyarsk.

E-mail: tatyana.gorbunova20@mail.ru

ГОСТа. Для изучения влияния полученных смесей на качество хлеба выбраны образцы смесей в количестве $20 \%$ средней фрракции. В готовых изделиях наблюдалось незначительное увеличение влажности, особенно с добавлением овсяного текстурата, это может быть связано с водопоглотительной способностью сырья после обработки. Пористость в отличие от контроля повысилась от 0,3 до 0,8 в зависимости от текстурата. Все показатели соответствуют требованиям качества. Таким образом, применение смесей из пшеничной муки с зерновыми текстуратами иелесообразно.

Ключевые слова: текстурат, хлеб, зерновое сырье, хлебобулочные изделия, мучные смеси.

The research objective was studying the influence of textured flour on the state of carbohydrate-amylase complex in flour mixtures for bread production. The research problems were to define experimentally the number of falling (NF) of grain texturates; to make 
mixtures with partial replacement of wheat flour by textured products; to study the state of NF of received mixtures; to conduct pilot studies of mixtures at bread production. The number of falling was defined according to State Standard 27676 on the device PChP-3. Using the indicator of the number of falling, the state of carbohydrate-amylase mixtures complex was defined. The mixtures were made of small, average and large fractions of the flour. The following texturate in wheat flour was brought: barley, oat and wheat. The replacement of wheat flour by the texturate was made in the quantity from 5 to $25 \%$. NF of flour mixtures on average decreased by $8 \%$ depending on the fineness of grinding and the type of entered textured product, but all the indicators remained within the requirement of State Standard specification. For studying the influence of received mixtures on the quality of bread the samples of mixtures in the number of $20 \%$ of average fraction were chosen. In finished products insignificant increase in humidity, especially with addition of oat texturate was observed, it could be connected with water absorbing ability of raw materials after processing. The porosity unlike control increased from 0.3 to 0.8 depending on the texturate. All the indicators conform to the requirements of quality. Thus, using the mixture of wheat flour with grain texturate is advisable.

Keywords: texturate, bread, grain raw material, bakery products, flour mixtures.

Введение. В настоящее время огромное значение уделяется качеству и безопасности продуктов питания. Основным продуктом массового потребления является хлеб, независимо от социального положения и статуса потребителей [1].

В последние годы существует тенденция увеличения качественной продукции, обогащенной пищевыми ингредиентами, для повышения пищевой ценности готовых изделий. Поиск и внедрение качественных ингредиентов является актуальной задачей $[2,5]$.

Основным сырьем для производства хлеба является мука. Теоретический и практический интерес для обогащения муки высшего сорта вызывает текстурированная мука из зернового сырья. Определенное количество амилолитических ферментов в тесте оказывает большое влияние на качество готового хлеба.

Получение продукта с требуемой активностью ферментов можно достичь путем смешивания пшеничной муки с текстурированной с различными значениями числа падения (ЧП) [3].

Цель исследования: изучение влияния текстурированной муки на состояние углеводноамилазного комплекса в мучных смесях для производства хлеба.

\section{Задачи исследования:}

1. Определить экспериментальным путем ЧП зерновых текстуратов.

2. Составить смеси с частичной заменой муки пшеничной на текстурированные продукты.

3. Изучить числа падения полученных смесей.

4. Провести экспериментальные исследования смесей при производстве хлеба.

Показатель числа падения характеризует активность амилолитических ферментов - амилаз.

Альфа- и бета-амилаза расщепляют крахмал и образуют сахара, которые необходимы для питания дрожжей, а также формируют вкус и цвет корочки хлеба [3].

Государственный стандарт предусматривает для хлебопекарной пшеничной муки нижний предел числа падения 160 с для муки 2-го сорта и обойной пшеничной муки и 185 с для остальных сортов. Верхний предел числа падения регламентом не предусмотрен, но слишком высокие значения его говорят о слишком низкой амилолитической активности ферментов, что негативно сказывается на процессе брожения теста и формировании его реологических свойств. Объемный выход готового хлеба уменьшается, продукт получается пресным на вкус, бледным и быстро поддается черствению $[1,4]$.

Если число падения ниже допустимого уровня, то клейковина в тесте становится слабой, тесто сильно расплывается. В готовых хлебобулочных изделиях снижается пористость и устойчивость формы, изделия имеют кислый вкус и солодовый запах $[1,2,5]$.

В ходе исследования проведены испытания числа падения пшеничной муки, зерновых текстуратов и мучных смесей пшеничной муки с различными текстуратами.

О состоянии углеводно-амилазного комплекса смеси пшеничной муки и текстурированных продуктов судили по показателю числа падения. Определение показателя ЧП проводили на приборе ПЧП-3 по методу, описанному в ГОСТ 27676 [1].

На рисунке 1 приведены показатели числа падения пшеничной муки высшего сорта и зерновых текстуратов. 


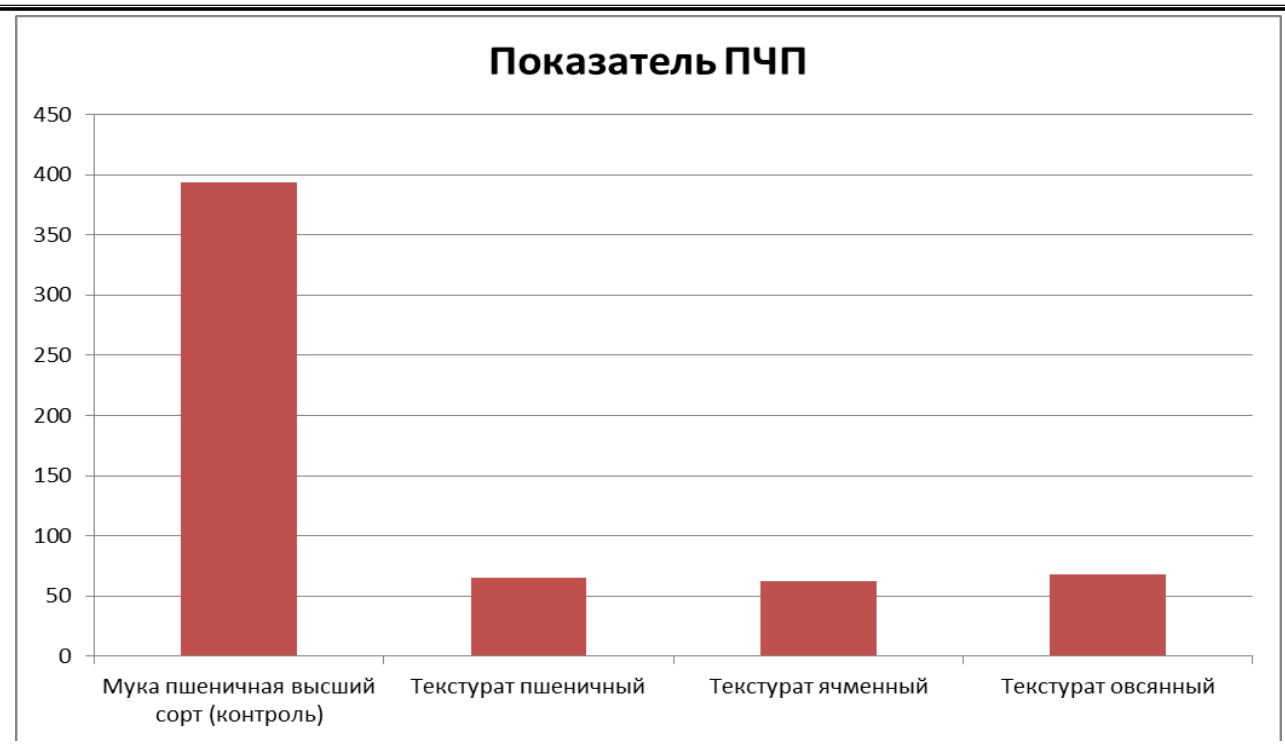

Puc. 1. Показатели числа падения муки пшеничной и текстурированных продуктов

На диаграмме видно, что показатели ЧП текстуратов в чистом виде ниже минимального предела, предусмотренного стандартом, тогда как показатель пшеничной муки высшего сорта составляет 394 с. Поэтому использование текстурированных зерновых продуктов в чистом виде для производства хлеба не подходит.

В ходе проведения эксперимента были составлены мучные смеси пшеничной муки выс- шего сорта с зерновыми текстуратами в количестве от 5 до $25 \%$ различных видов и в зависимости от крупности помола.

На рисунках 2-4 приведены диаграммы показателей числа падения с частичной заменой пшеничной муки на текстураты зерновые в зависимости от размера фракции.

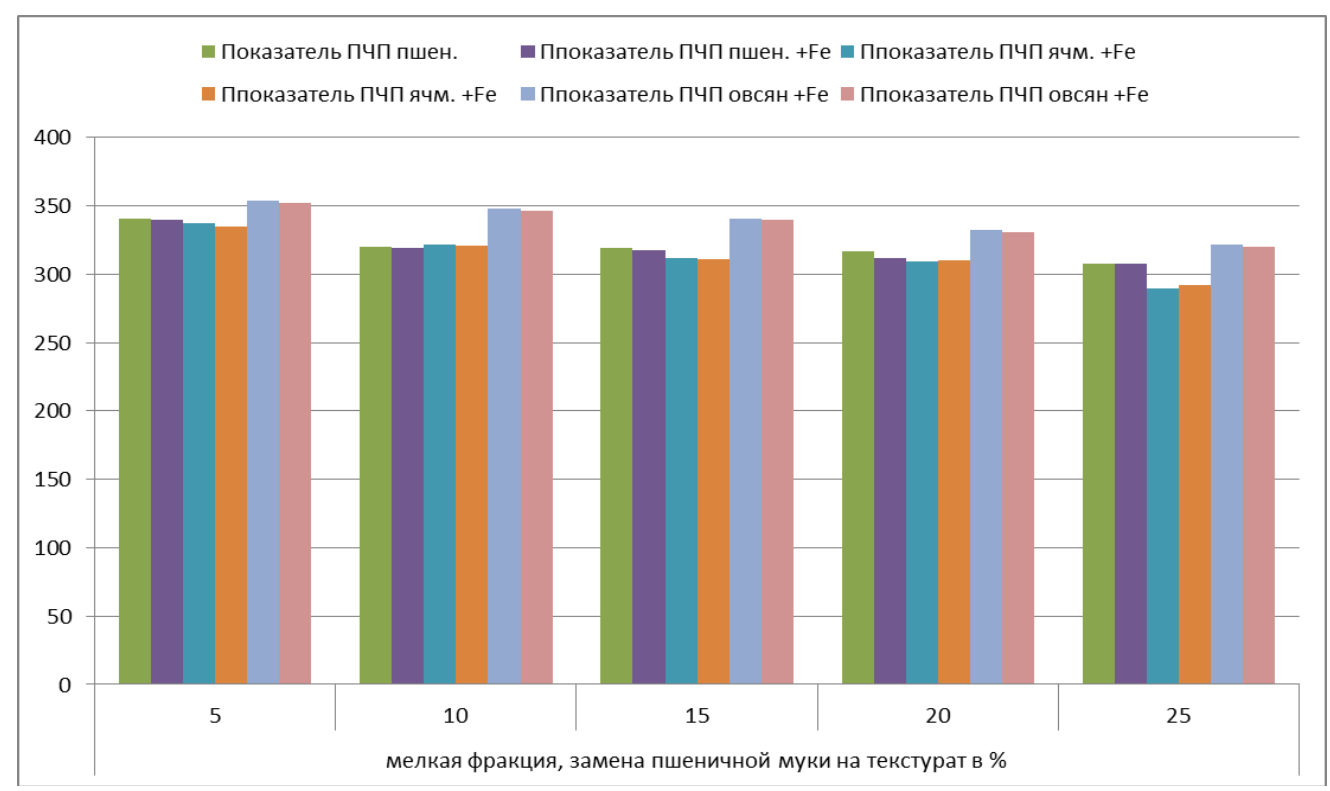

Puc. 2. Показатели ЧП мелкой фрракции смесей с заменой муки от 5 до 25 \% 


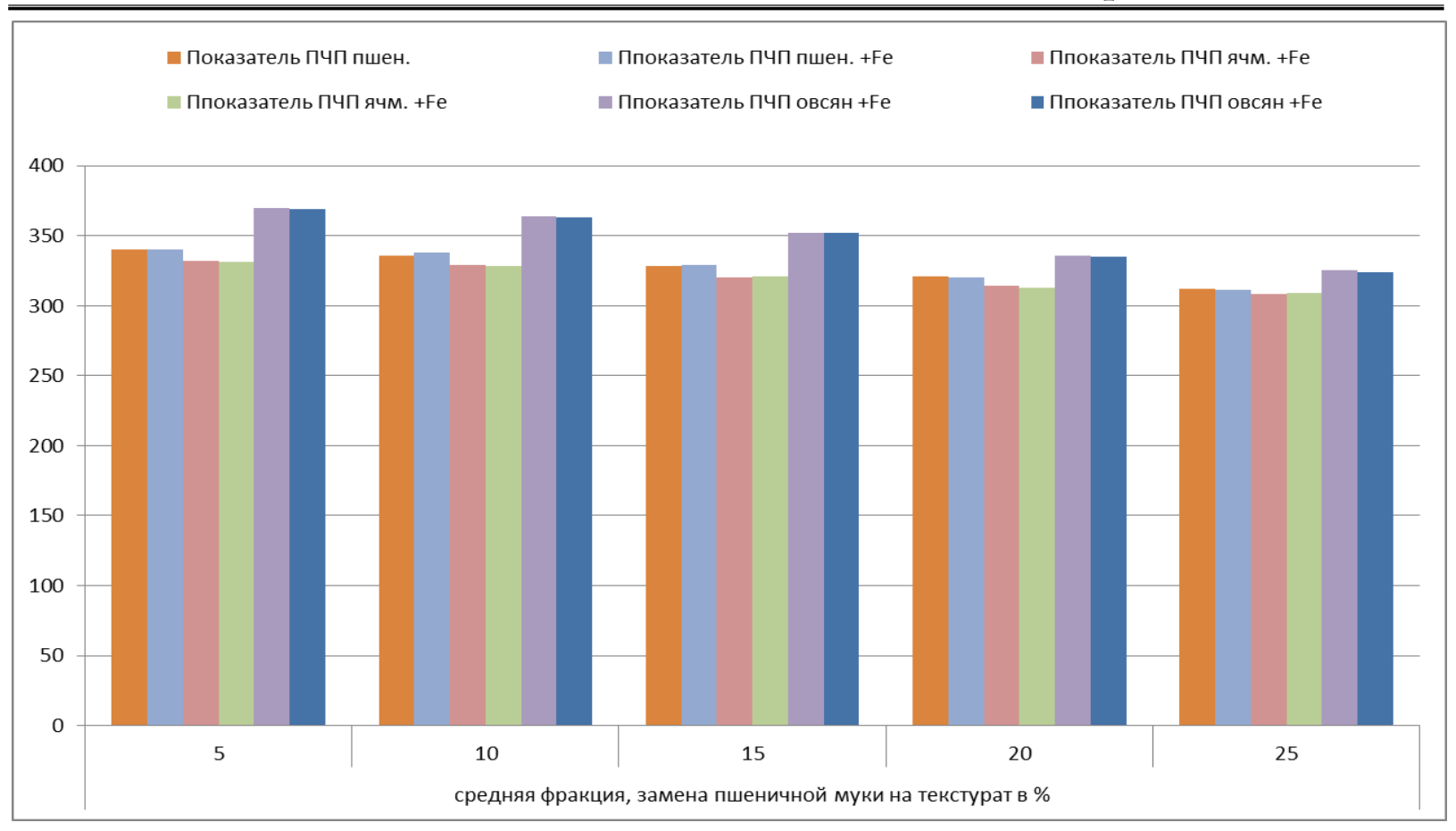

Puc. 3. Показатели ЧП средней рракции смесей с заменой муки от 5 до 25 \%

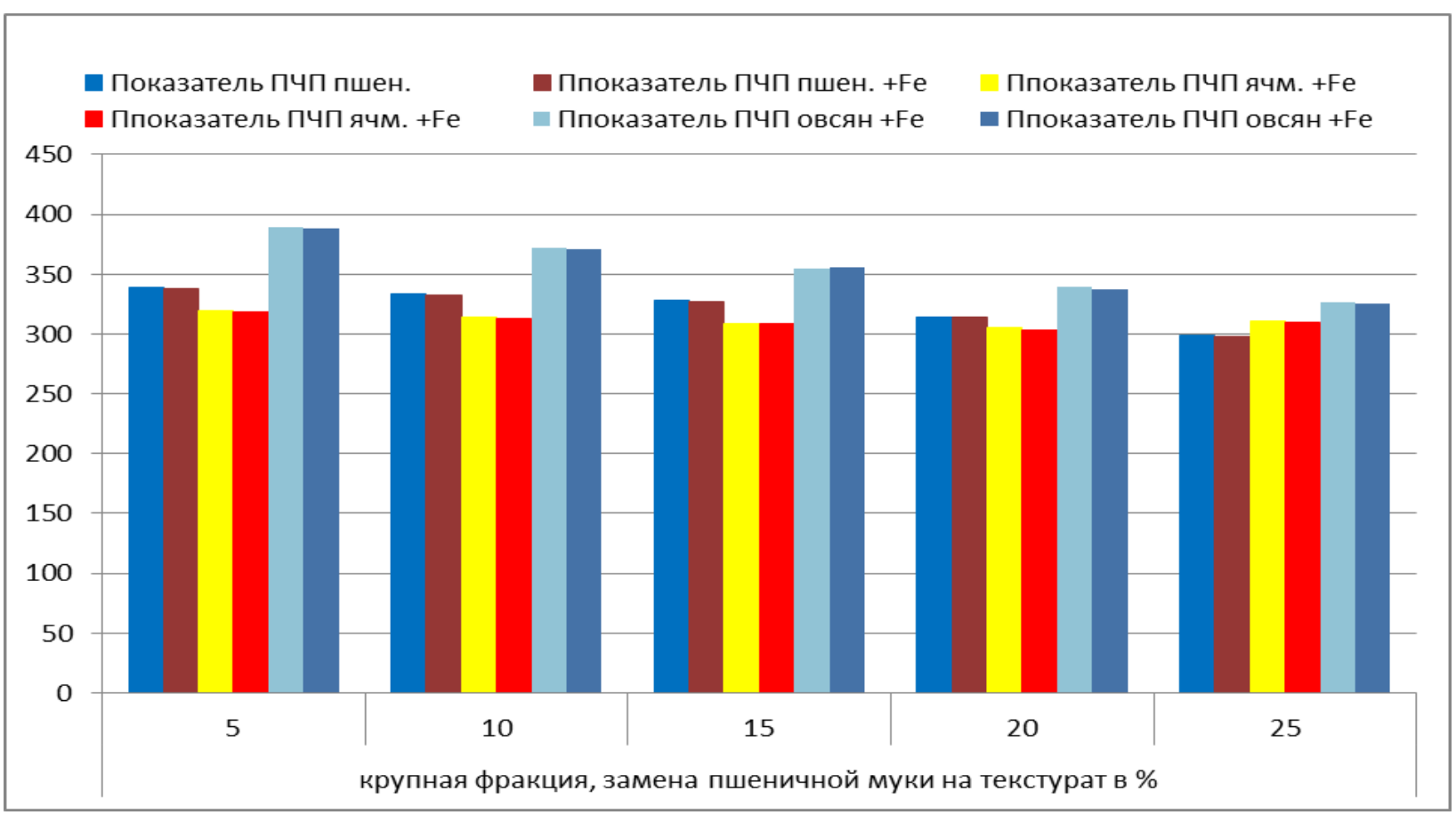

Puc. 4. Показатели ЧП крупной фрракции смесей с заменой муки от 5 до 25 \%

В результате проведения эксперимента установлено, что при внесение текстурированных продуктов в состав смесей с пшеничной мукой способствует снижению вязкости водно-мучной суспензии [1]. Внесение текстурированных продуктов из экструдированного зерна пшеницы, ячменя и овса в количестве от 5 до 25 \% приводило к уменьшению ЧП мучной смеси от 9,8 до 7,3 \% в зависимости от крупности помола и вида вводимого текстурированного продукта.

В мучной смеси с применением текстурата овса, если сравнивать его с контрольным об- 
разцом, показатель ЧП снизился меньше, чем в смесях с применением текстуратов пшеницы и ячменя.

Увеличение крупности помола способствует снижению вязкости водно-мучной суспензии фрактически у всех мучных смесей с применением текстуратов злаковых культур. Обогащение текстуратов микроэлементами не повлияло на показатель числа падения.

Простые углеводы, которые образуются в результате обработки зернового сырья с помощью экструзии, явились дополнительным веществом для работы амилаз, что способствует снижению числа падения муки пшеничной [1].

Использование текстурированных продуктов будет способствовать ускорению созревания теста из пшеничной муки с пониженной активностью амилолитических ферментов [1].

Показатели ЧП всех исследуемых мучных смесей превышают минимальные значения числа падения согласно требованиям ГОСТа. Самые низкий показатель ЧП (290 с) зафиксирован в смеси с ячменным текстуратом в количестве $25 \%$ мелкой фракции. Самый высокий показатель (389 с) достигнут в сочетании пшеничной муки с овсяной крупной фрракции в количестве $5 \%$

Для изучения влияния тектстурированных продуктов на качество хлеба за контроль была взята рецептура хлеба пшеничного из муки высшего сорта. Образец № 1 - рецептура из смеси муки с текстуратом пшеничным средней фрракции в количестве $20 \%$, образец № 2 - рецептура из смеси муки с текстуратом ячменным средней фракции в количестве $20 \%$, образец № 3 - рецептура из смеси муки с текстуратом овсяным средней фрракции в количестве $20 \%$.

Результаты показателей качества полученных изделий приведены в таблице.

\section{Показатели качества хлеба}

\begin{tabular}{|l|c|c|c|c|}
\hline \multicolumn{1}{|c|}{$\begin{array}{c}\text { Показатель } \\
\text { качества }\end{array}$} & $\begin{array}{c}\text { Хлеб пшеничный } \\
\text { (контроль) }\end{array}$ & $\begin{array}{c}\text { Хлеб пшеничный } \\
\text { с текстуратом } \\
\text { пшеничным }\end{array}$ & $\begin{array}{c}\text { Хлеб пшеничный } \\
\text { с текстуратом } \\
\text { ячменным }\end{array}$ & $\begin{array}{c}\text { Хлеб пшеничный } \\
\text { с текстуратом } \\
\text { овсяным }\end{array}$ \\
\hline Влажность, \% & 42,3 & 42,3 & 42,2 & 42,7 \\
\hline Кислотность, град. & 2,8 & 2,4 & 2,44 & 2,3 \\
\hline Пористость, \% & 72 & 72,5 & 72,3 & 72,8 \\
\hline $\begin{array}{l}\text { Формоустойчи- } \\
\text { вость, H/D }\end{array}$ & 0,46 & 0,48 & 0,47 & 0,44 \\
\hline
\end{tabular}

Из таблицы 1 видно, что с введением в муку пшеничную часть тестурированных продуктов приводит к незначительному увеличению влажности, особенно с добавлением овсяного текстурата, это может быть связано с водопоглотительной способностью сырья после обработки. Кислотность в образцах снизилась: с пшеничным текстуратом - на 0,4 град., с ячменным - на 0,36 и с овсяным текстуратом - на 0,5 град. Пористость в отличие от контроля повысилась от 0,3 до 0,8 в зависимости от текстурата. Все по- казатели остаются в пределах требования ГОСТ P 56631-2015.

Дегустационную (органолептическую) оценку хлеба проводили по 5-балльной системе. Результаты представлены на рисунке 5 .

Все образцы хлеба набрали высокие баллы, цвет корки с добавлением текстурированных продуктов улучшался, появлялся характерный запах текстурата и вкус. Наивысшие баллы получил образец № 3 с добавлением овсяного текстурата. 


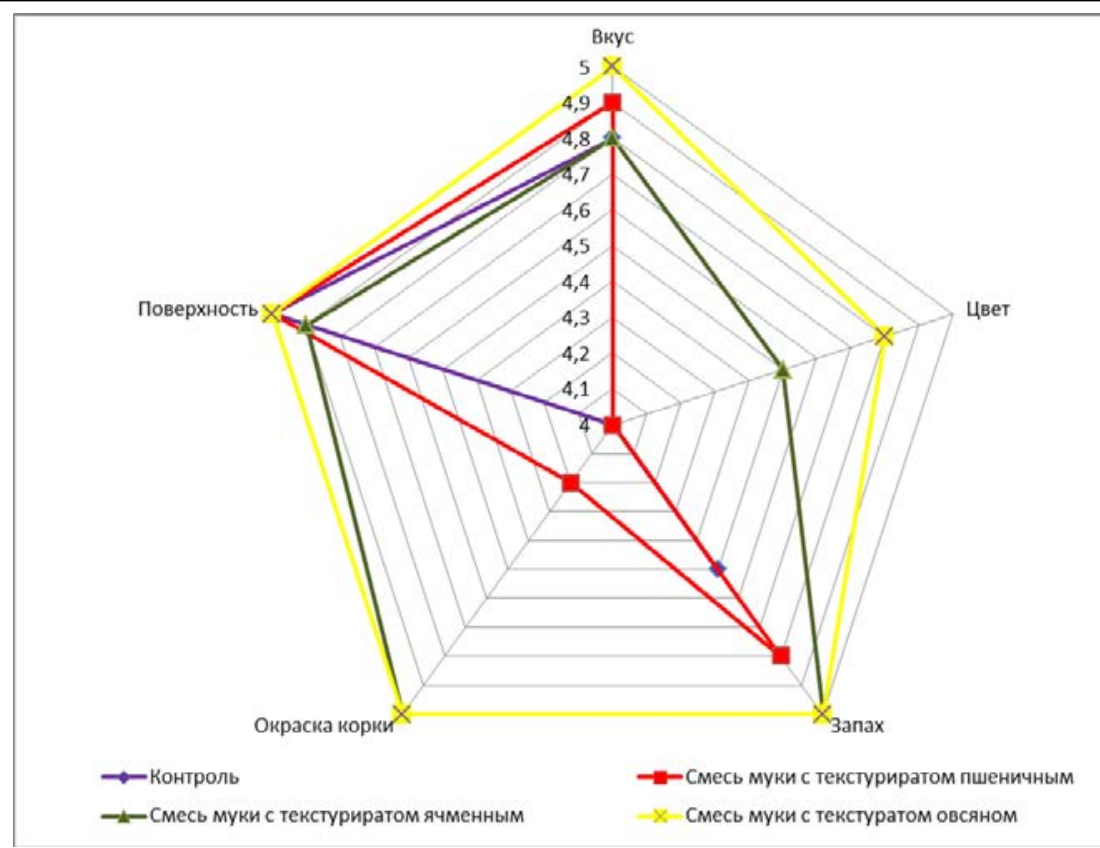

Puc. 5. Результаты органолептической оценки хлеба на основе зерновых текстуратов

Выводы. По результатам исследования можно сделать вывод, что при частичной замене пшеничной муки на зерновые текстураты число падения смеси остается в пределах требований ГОСТа. Внесение текстуратов оказывает положительное влияние на автолитическую активность муки и ее хлебопекарные свойства. Выпеченный хлеб из полученных смесей получается хорошего качества, обладает высокими органолептическими показателями. Физикохимические показатели качества хлеба соответствуют требованиям. В хлебе из смеси с текстуратами повышается влажность готового изделия, что позволит увеличить выход продукта.

Таким образом, применение смесей из пшеничной муки с зерновыми текстуратами целесообразно.

\section{Литература}

1. Жиркова Е.В., Мартиросян В.В. Перспективы применения отечественных экструзионных ингредиентов в хлебопекарном производстве // Хлебопродукты. - 2016. - № 2.

2. Краус С.В., Балаева Е.В., Бочагов Е.А., Денисюк И.А. Использование экструдированной пшеничной муки при производстве кондитерских изделий // Хлебопродукты. - 2012. № 8. - C. 58-60.

3. Магомедов Г.О., Брехов А.Ф., Черных В.Я., Юрьев В.П. Экструзионная технология пищевых продуктов // Пищевая промышленность. -2003 . - № 12. - С. 10-14.
4. Малкина В.Д., Мартиросян В.В., Жиркова E.B. Модификация свойств растительного сырья в процессе экструзионной обработки. Пятигорск: КМВ, 2013. - 165 с.

5. Шмалько Н.А., Беликова А.В., Росляков Ю.Ф. Использование экструдированных продуктов в хлебопечении // Фундаментальные исследования. - 2007. - № 7. - С. 90-92.

\section{Literatura}

1. Zhirkova E.V., Martirosyan V.V. Perspektivy primeneniya otechestvennyh ekstruzionnyh ingredientov $\mathrm{v}$ hlebopekarnom proizvodstve /I Hleboprodukty. - 2016. - № 2.

2. Kraus S.V., Balaeva E.V., Bochagov E.A., Denisyuk I.A. Ispol'zovanie ekstrudirovannoj pshenichnoj muki pri proizvodstve konditerskih izdelij // Hleboprodukty. - 2012. - № 8. - S. 58-60.

3. Magomedov G.O., Brekhov A.F., Chernyh V.Ya., Yur'ev V.P. Ekstruzionnaya tekhnologiya pishchevyh produktov // Pishchevaya promyshlennost'. - 2003. - № 12. - S. 10-14.

4. Malkina V.D., Martirosyan V.V., Zhirkova E.V. Modifikaciya svojstv rastitel'nogo syr'ya $\mathrm{V}$ processe ekstruzionnoj obrabotki. - Pyatigorsk: $\mathrm{KMV}, 2013 .-165 \mathrm{~s}$.

5. Shmal'ko N.A., Belikova A.V., Roslyakov Yu.F. Ispol'zovanie ekstrudirovannyh produktov $v$ hlebopechenii // Fundamental'nye issledovaniya. - 2007. - № 7. - S. 90-92. 